\title{
Photoinhibition of photosynthesis in marine macrophytes of the South China Sea
}

\author{
Dieter Hanelt
}

Fachbereich Biologie - Botanik, Philipps-Universität, Lahnberge, W-3550 Marburg, Germany

\begin{abstract}
Photoinhibition of photosynthesis was investigated along the coast of Hainandao, an island in the tropical zone of the South China Sea, in autumn 1990. Experiments were carried out with a portable fluorometer and an oxygen-measuring system constructed especially for field studies. The daily courses of photoinhibition of different algal species and of a seagrass were investigated. Results showed that the highest degree of photoinhibition occurred between noon and afternoon. In the late afternoon and in the evening photosynthetic capacity recovered. The extent of photoinhibition depended on the turbidity of the water, e.g. on a sunny day with high photon fluence rates (PFR) the algae were hardly photoinhibited, when the surf and, hence, the turbidity was high. The photosynthetic capacity depended exclusively on the PFR and did not underlie any circadian rhythms in the photosynthetic activity. Different species show different sensitivities at comparable light conditions, reflecting the importance of photoinhibition for the algal zonation pattern in the littoral.
\end{abstract}

\section{INTRODUCTION}

Most investigations of photoinhibition have been carried out in laboratories, whereas little work has been done in the field. Field experiments with the higher plant Salix showed that photoinhibition occurs on sunny days and that photosynthesis recovers fully during sunset and night (Ögren 1988). Demmig-Adams et al. (1989) obtained comparable results with Arbutus unedo. The diurnal course of the incident photon flux density on a sunny day approximates a parabola, beginning at sunrise, with a maximum at midday and ending at sunset (Ramus 1981). However, the surf diatom Anaulus australis shows a depression of photosynthesis rather than a maximum at midday, and full recovery was measured during the night (Preez et al. 1990). In outdoor glass tanks at a constant water level benthic marine algae show a morning maximum in photosynthesis, an afternoon depression and a late afternoon recovery (Ramus \& Rosenberg 1980). In Sargassum horneri the afternoon depression disappeared when the solar radiation was reduced (Gao 1990).

In the marine littoral, however, considerable changes of the photon fluence rate (PFR) under water are also caused by the tides. Thus, the diurnal course of photosynthesis depends on the diurnal course of light conditions, which in turn depend on the angle of the incident sun ray, atmospheric disturbance and the tide level. Huppertz et al. (1990) studied the diurnal course of photosynthesis and photoinhibition of Fucus serratus, growing in the intertidal belt. Algae were collected on the rocky shore of Helgoland, Germany, a small island in the cold temperate zone of the SE North Sea. A considerable decrease of photosynthetic capacity occurred during falling tide. Conservation of the photoinhibitory state by desiccation was observed. When the PFR decreased, recovery commenced and photosynthetic capacity increased. Full recovery was reached either at sunset or during the night.

Photoinhibition is thought to be due to a breakdown of D1-protein and, hence, depends on temperature. Richter et al. (1990) reported that the breakdown of D1protein as well as the concomitant loss of variable fluorescence were largely prevented when spinach thylakoids were photoinhibited at $0^{\circ} \mathrm{C}$. However, isolated thylakoids of irradiated Cucurbita leaves showed a faster photoinhibition of photosystem II (PSII) at low temperature (Aro et al. 1990); in the duck-weed Lemna gibba increasing temperature decreased the degree of photoinhibition (Gong \& Nielsen 1989). This may be due to the interaction of photoinhibition and the recovery processes which also depend on temperature. Greer et al. (1986) observed that in Phaseolus the rate of recovery was slow below $15^{\circ} \mathrm{C}$ and optimal at $30^{\circ} \mathrm{C}$. 
Moreover, recovery of photosynthesis requires low photon fluence rates (Greer et al. 1986, Nultsch et al. 1987). In the tropics water temperature is higher and the dusk period shorter than in the North Sea. Thus the question arose whether tropical algae show both a stronger photoinhibition and a faster recovery of photosynthesis.

\section{MATERIAL AND METHODS}

A joint expedition of the Senckenberg Research Institut (Frankfurt, Germany) and the Academia Sinica (Qingdao, China) enabled an expedition to Hainandao, an island in the South China Sea, where field experiments were conducted with benthic marine algae and 1 seagrass in November and December 1990.

Most of the experiments were carried out in Xiaodonghai Bay, south coast of Hainandao near the city Sanya. Macroalgae in this area grow in the sublittoral on a partially dead coral reef. Algae were collected in a depth between 1.2 and $2.0 \mathrm{~m}$, measured at low tide. Additional experiments were conducted near Meixia and Haikou, on the north coast of Hainandao. Algae at the Meixia site were collected from a coral reef beneath the water surface at low tide. At Haikou, algae were collected from pools at a Gracilaria farm.

In vivo chlorophyll fluorescence was measured with a portable pulse-amplitude-modulation fluorometer (PAM, Walz, Effeltrich, Germany) connected with a saturation pulse lamp, as devised by Schreiber et al. (1986). As a measure for photoinhibition, the ratio of variable fluorescence to maximal fluorescence $F_{V} / F m$ [where $F V=F m-F_{O}$, in which $F_{O}=$ initial fluorescence, i.e. when all reaction centers of PSII are active or 'open', and $F m=$ maximal fluoresence, i.e. when they are 'closed'] was used (cf. Krause \& Weis 1991). Pieces of macrophytes were collected under water and placed into a black vessel for transportation. Discs were cut out of the phylloids, and transferred into a special seawater cuvette surrounded by a cooling jacket, and kept in the dark for $10 \mathrm{~min}$. Initial fluorescence $(F o)$ was then measured with a modulated red measuring light of a very low photon fluence rate. Frn was determined with a $700 \mathrm{~ms}$ overall saturating white light pulse. (For more details see Huppertz et al. 1990.)

The oxygen production of a thallus disc was measured with a temperature-compensated Clark electrode (Oxi 92, WTW, Germany) under natural light and temperature conditions. The measuring device, especially developed for field experiments, is described in detail by Huppertz et al. (1990). In contrast to the fluorescence measurements only 1 disc was cut out of a macrophyte under water, put into the oxygen cuvette and exposed to the daylight the whole time. If possible the cuvette was fastened to the ground at the surf zone, and the device adapted to the temperature of the seawater. If the surf was too strong so that the cuvette could not be fastened to the ground, it was placed in a seawater-filled bucket. Water in the bucket was renewed periodically with fresh seawater to cool the device. The window of the cuvette was horizontally oriented. Incident irradiance was diminished by ca $6 \%$ by the glass window and the plexiglass plate in the cuvette. Transmittance of the cuvette window for wavelengths $<350 \mathrm{~nm}$ decreases, and wavelengths $<300 \mathrm{~nm}$ are totally absorbed. In order to measure photoinhibition state, the alga in the cuvette was irradiated with a measuring light of a constant photon fluence rate produced by a battery-powered light emitting diode surrounded by a cap (Fig. 1). This LED-cap was put on the top of the cuvette temporarily, and the alga was then irradiated with a constant PFR of 130 umol m $\mathrm{m}^{-2} \mathrm{~s}^{-1}$ of $650 \mathrm{~nm}$ red light for only a few minutes. This PFR was not high enough to measure photosynthetic capacity above saturating PFRs. Nevertheless, a change in the photosynthetic capacity also causes a change in the photosynthetic efficiency at non-saturating PFRs (Nultsch et al. 1990). Thus, a change in $\mathrm{O}_{2}$ production caused by the standard red light indicates also a change of the degree of photoinhibition. Oxygen production values are composed of photosynthetic $\mathrm{O}_{2}$ evolution, respiration rate of the algal sample as well as respiration of bacteria in the natural seawater and $\mathrm{O}_{2}$ consumption by the Clarkelectrode. Moreover, red light has a lower photosynthetic efficiency than white light so that $\mathrm{O}_{2}$ production appears lower than one would expect from the high PFR.

Irradiance in air and under water was measured with a LI-COR radiationmeter (LI-COR, Lincoln, NB, USA) equipped with quantum sensors and a specific photodetector for continuous recording of the daylight PFR, described by Hanelt \& Nultsch (1990).

In autumn 1990 only very young algae were found in the intertidal zone. As they were mostly too small for our experiments, large thalli had to be collected in the sublittoral.

\section{RESULTS}

Fig. 2 shows the results of an experiment with Padina sp., a brown alga ( $P$. boryana or $P$. minor; it was not possible to distinguish these 2 species in the field). FV/ Frm was used as a measure for the potential yield of the photochemical reaction of PS II. Environmental stresses affecting PS II efficiency lead to a decrease in $F v / F m$. Thus, the lower the $F_{V} / F m$ value is, the higher is the degree of photoinhibition. In addition the PFR of daylight is shown, which was continuously measured in 
Fig. 1. Oxygen cuvette mounted on a coral reef in the surf zone. The cap with the LED is held beside the $\mathrm{O}_{2}$ cuvette. The algal disc is located in the middle of the plexiglass cuvette facing the sky

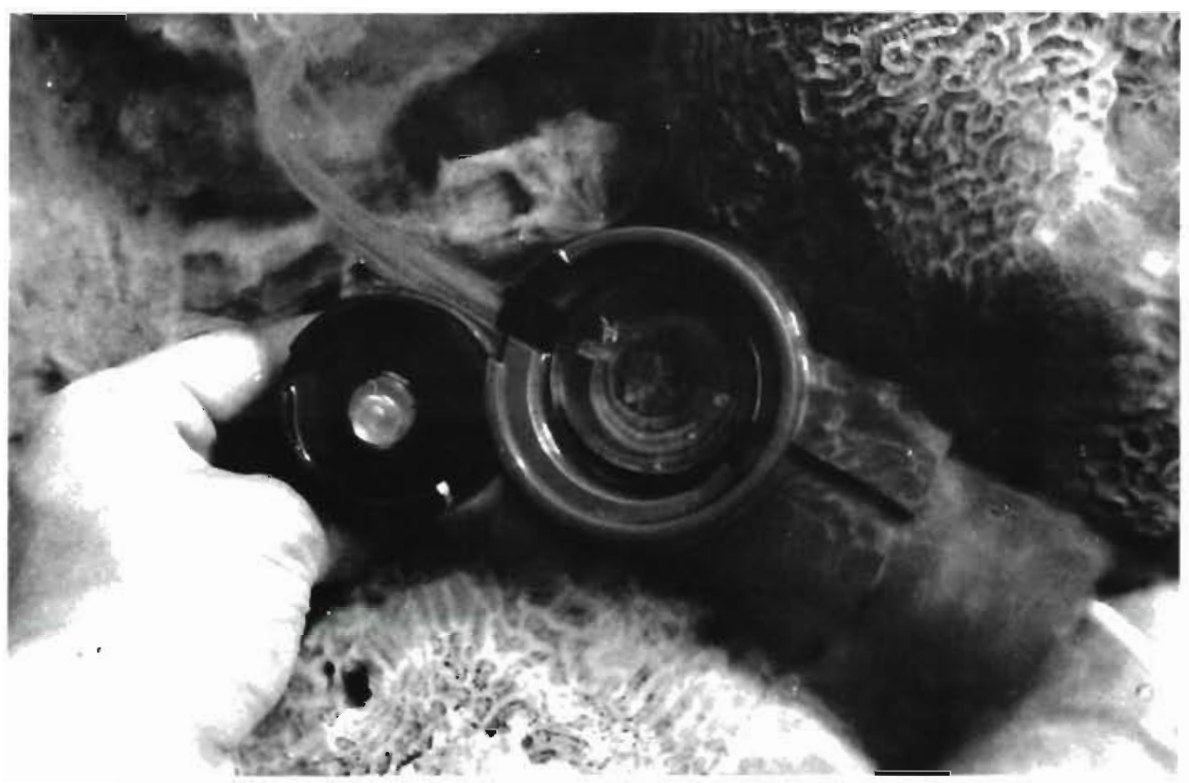

air, indicating a sunny day. For clearer presentation the irradiance values were averaged for every $10 \mathrm{~min}$. Low tide was at 09:25 $\mathrm{h}$; the tide difference was about $1.15 \mathrm{~m}$. The experiment started on rising tide. At a depth of $1.2 \mathrm{~m} 50 \%$ of the PFR above the water surface was measured. The $F_{V} / F m$ of a non-photoinhibited Padina sp. was about 0.75 , the $F V / F m$ of the algal disc collected at 14:00 h was 0.38 , indicating a high degree of photoinhibition. In the afternoon, with decreasing PFR and rising tide, the degree of photoinhibition decreased simultaneously and recovery of photosynthesis commenced. In the evening the photosynthetic capacity had fully recovered.

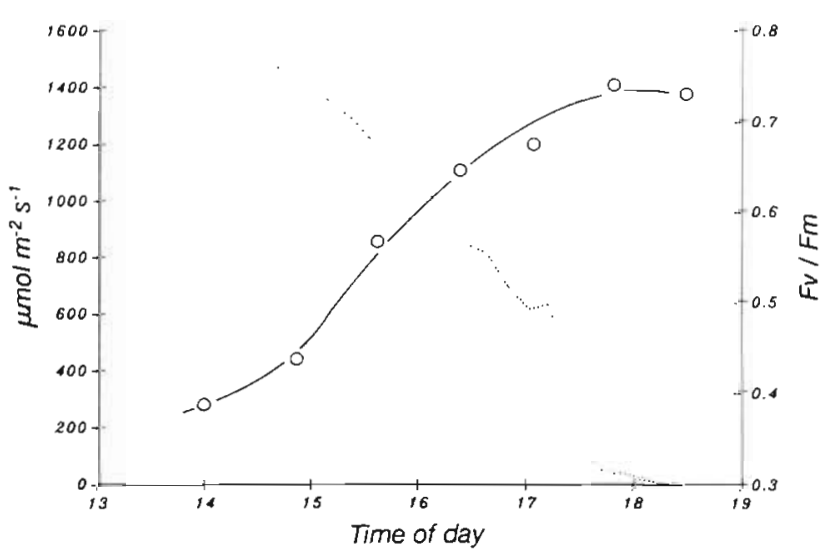

Fig. 2. Padina sp. Ratio of variable to maximum fluorescence $(0-0)$ of thalli growing in the sublittoral of the Xiaodonghai Bay on a sunny day. Photon fluence rate of daylight $(\cdots \cdot)$ measured in air during the day. Left ordinate: photon fluence rate of daylight; right ordinate: ratio of variable to maximum fluorescence
The results obtained on a cloudy day are shown in Fig. 3. Low tide was at 08:40 h. High turbidity resulted in only $37 \%$ of the daylight being measured at $1.2 \mathrm{~m}$ depth. The low PFR under water caused no significant decrease of the $F$ V/Fm value (Fig. 3, line with open circles). Immediately after the first fluorescence measurement each algal disc was placed into a Petri dish filled with seawater, irradiated for $15 \mathrm{~min}$ with full daylight, and the fluorescence ratio determined again (Fig. 3, line with solid circles). The $F V / F m$ of the first disc at 13:50 h decreased from 0.74 to the low value of 0.43 , indicating a high degree and a fast photoinhibition. After 15:10 h the PFR of daylight decreased and,

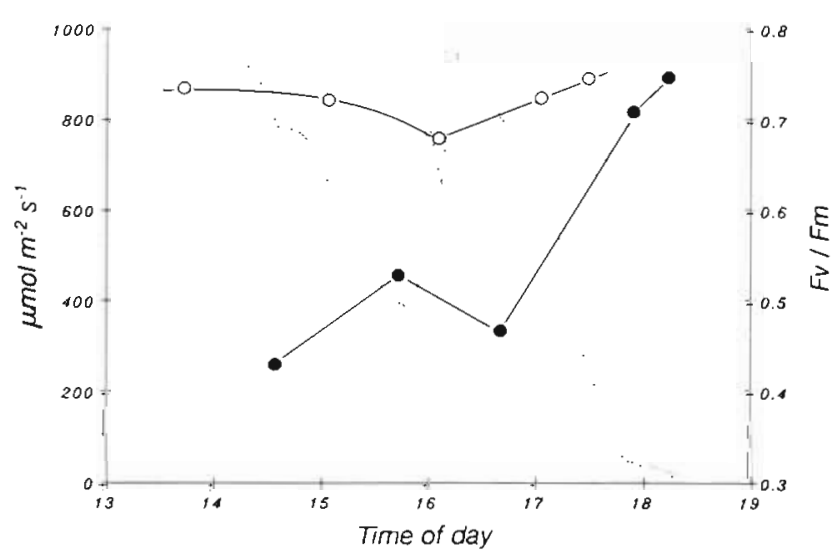

Fig. 3. Padina sp. Ratio of variable to maximum fluorescence (-) of thalli growing in the sublittoral zone, on a cloudy day. Fluorescence measured again $(\bullet)$ after the thalli were exposed to the full daylight for $15 \mathrm{~min}$. Photon fluence rate of daylight $(\cdots \cdot)$ measured in air continuously during the day. Ordinates as in Fig. 2 
thus, the degree of photoinhibition of the second sample measured at 15:40 h was lower. An increase of the PFR at 16:00 h caused a decrease of the $F_{V} / F_{m}$ value of the third sample again. After 17:30 h, during sunset, the PFR was too low to cause photoinhibition, so that no significant change of the $F V / F m$ of the fourth and fifth algal disc was observed. These results show that Padina sp. reaches a high degree of photoinhibition within $15 \mathrm{~min}$ and, hence, reacts very fast.

Results obtained on a sunny day but with a low light transmittance of the water body are shown in Fig. 4.

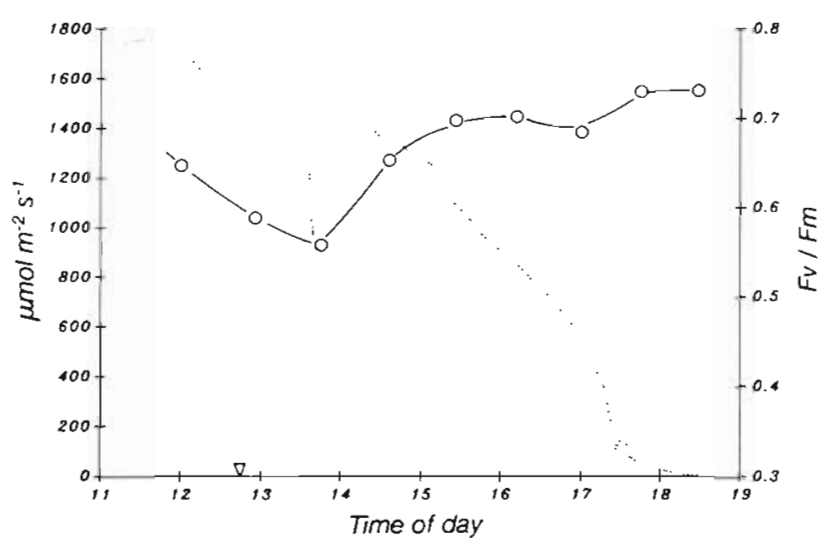

Fig. 4. Padina sp. Ratio of variable to maximum fluorescence $(0)$ of thalli which were collected in the sublittoral at a low light transmittance of the water body. Photon fluence rate of daylight $(\cdots \cdots)$ measured in air during the day. Arrow on the abscissa indicates time of low tide. Ordinates as in Fig. 2

Only $37 \%$ of the incident light on the water surface was measured at $1.2 \mathrm{~m}$ depth. Low tide occurred at 12:50 h. The FV/Fm value decreased with falling tide at a high PFR of daylight. After 14:00 h the $F_{V} / F m$ value increased due to the decreasing PFR of the daylight and the rising tide. At $13: 40 \mathrm{~h}$ a transient clouding occurred during the collection of the next algal sample. Thus, the decrease in the PFR was too short to cause an increase in the photosynthetic capacity.

Sargassum sp. was collected at a depth of $1.2 \mathrm{~m}$. The transmitted light was $45 \%$ of the full daylight. The species could not be determined, because the thalli were too young. The $F_{V} / F m$ value measured at midday (Fig. 5) was still relatively high, but decreased continuously until 14:50 h despite transient clouding. Although the irradiance at 14:50 h was lower than at 12:00 h, the degree of photoinhibition at 14:50 h was higher, since the tide was still falling at 12:00 $\mathrm{h}$ and low tide was reached at 14:30 h. In the evening photosynthesis had fully recovered. Due to a strong absorption and scattering of light in the turbid water body, the falling water level caused a fast increase of the irradiance impinged on the algae. It may be that the increase of the transmit-

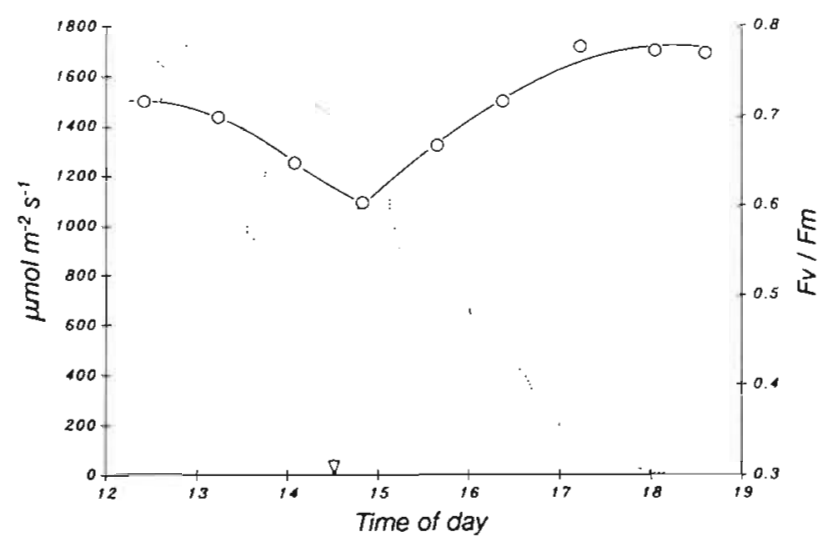

Fig. 5. Sargassum sp. Ratio of variable to maximum fluorescence $(0-0)$ of thalli in the sublittoral of Xiaodonghai Bay Photon fluence rate of daylight $(\cdots \cdot)$ measured in air continuously during the day. Arrow on the abscissa indicates time of low tide. Ordinates as in Fig. 2

ted light was faster than the decrease of the PFR at the surface. This would explain the lowest FV/Fm value and, hence, the highest degree of photoinhibition at low tide.

A different course of photoinhibition during 2 successive days with different courses of PFR is shown in Fig. 6. At Meixia Sargassum glaucescens grows beneath the water surface at low tide. Fig. 6a shows an experiment on a sunny day. With falling tide Fv/Fm decreased until about 15:00 h, and then it increased because the PFR of daylight was no longer high enough to cause strong photoinhibition. On the previous day (Fig. 6b) a strong clouding caused a low PFR. Thus, the algae, collected at the same location, showed only a slight photoinhibition. Measurements of $\mathrm{O}_{2}$ production confirmed the results of the fluorescence measurements with $S$. glaucescens. The algal sample for the $\mathrm{O}_{2}$ experiment was collected at a depth of about $0.5 \mathrm{~m}$ at a low transmittance $(63 \%$ in about $15 \mathrm{~cm})$. The result is shown in Fig. 7. The top of the cuvette was above the water surface and, hence, the PFR of daylight was not attenuated by turbid water. Consequently, photosynthetic activity (Fig, 7, line fit to small points) decreased quickly due to photoinhibition. After adaptation to the new environment $\mathrm{O}_{2}$ production increased and reached a relatively constant level for $2 \mathrm{~h}$. After 17:00 h the PFR was too low to saturate photosynthesis, and $\mathrm{O}_{2}$ production decreased according to the decreasing PFR. The photosynthetic efficiency measured as oxygen production at a constant PFR of $130 \mu \mathrm{mol} \mathrm{m} \mathrm{m}^{-2} \mathrm{~s}^{-1}$ of red light is shown by the line with open circles in Fig. 7. Initially, both the photosynthetic activity caused by the daylight and the efficiency decreased. This indicates the occurrence of a higher degree of photoinhibition. After 14:10 h a continuously increasing photosynthetic efficiency in rela- 

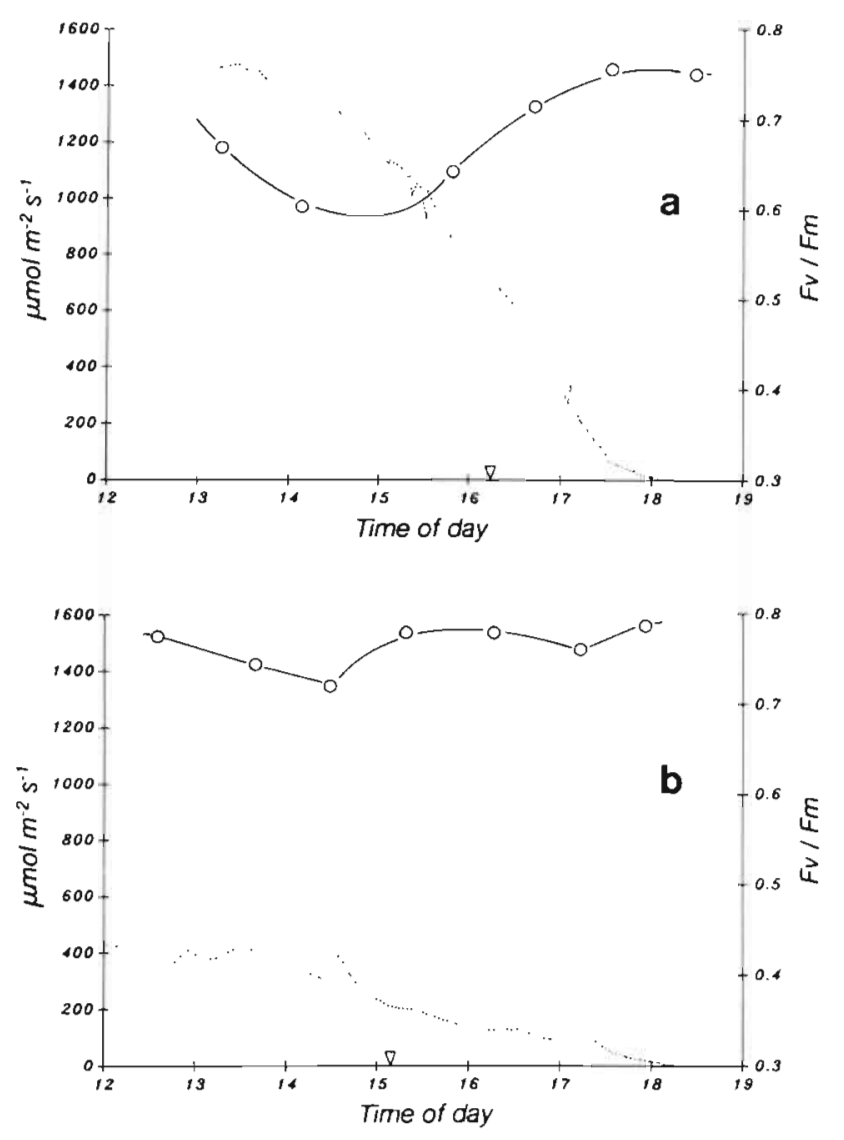

Fig. 6. Sargassum glaucescens. As in Fig. 5, but thalli collected in the upper sublittoral zone at Meixia. (a) Ratio of variable to maximum fluorescence on a sunny day and (b) on a cloudy day at the same location

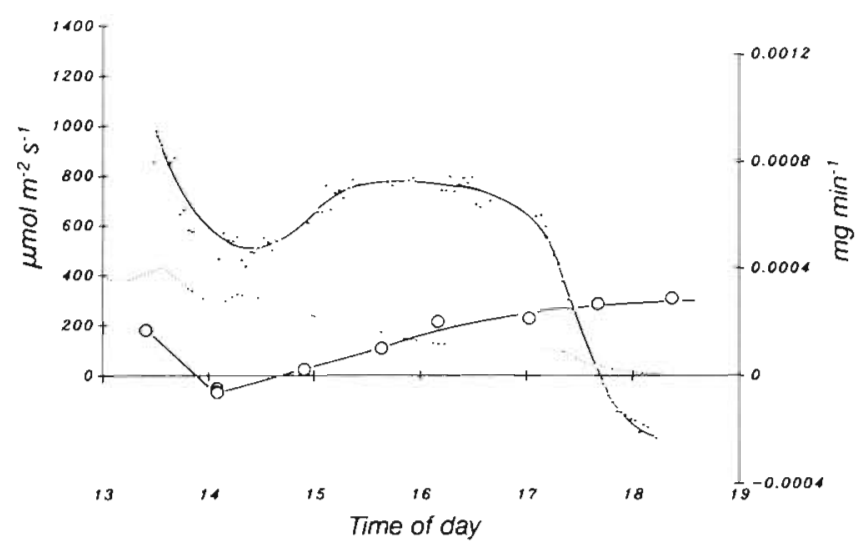

Fig. 7. Sargassum glaucescens. Photosynthetic activity of a thallus disc in situ exposed to the daylight near the water surface on a cloudy day (line fit to small points). Photosynthetic efficiency of the same thallus $(0-0)$ measured with 130 $\mu \mathrm{mol} \mathrm{m} \mathrm{m}^{-2} \mathrm{~s}^{-1}$ of $650 \mathrm{~nm}$ control light for a few minutes. Photon fluence rate of daylight ( ....) measured in air continuously during the day. Left ordinate: photon fluence rate of daylight; right ordinate: $\mathrm{O}_{2}$ production tion to the decreasing PFR of daylight indicates the recovery of photosynthesis. In comparison to Padina sp., S. glaucescens required a higher PFR to cause the same degree of photoinhibition at the same conditions.

The brown alga Lobophora variegata grows in Meixia on blocks of the coral reef in the lower intertidal and upper subtidal zone. The thalli used for these experiments grew on a block which emerged at about 15:00 h. The algae leaned against the block at different angles and overlapped in clusters, so that the photon fluence absorbed varied strongly from thallus to thallus. Thus, the low values of $F_{V} / F_{m}$ also differed (Fig. 8a). Nevertheless, a significant photoinhibition was
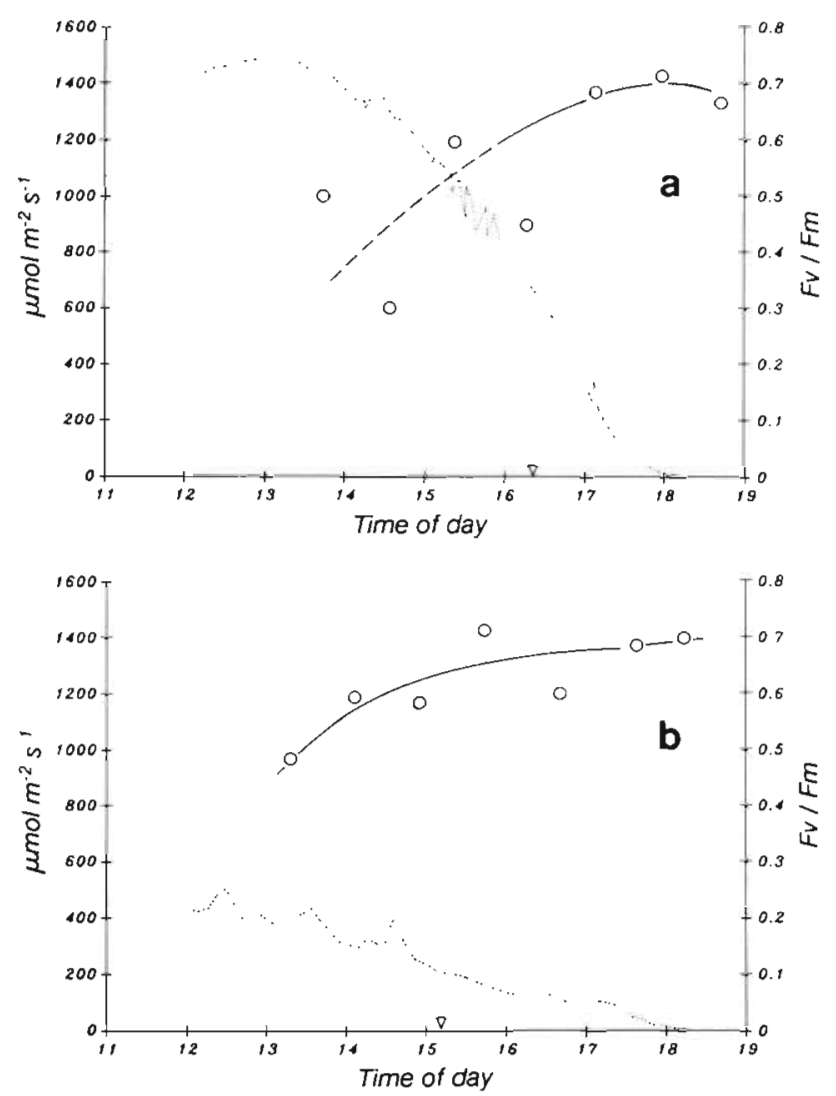

Fig. 8. Lobophora variegata. As in Fig. 6 with $L$. variegata disc as sample (a) on a sunny day and (b) on a cloudy day

observed between 13:40 h and 16:20 h. At 18:00 h full recovery was reached. On the prior day, the sky was cloudy and the PFR was low (Fig. 8b). Therefore, only a low degree of photoinhibition was measured at 13:20 h. With decreasing PFR the FV/Fm increased, until at 18:00 h full recovery was reached. After an algal disc was put into the $\mathrm{O}_{2}$ cuvette, $\mathrm{O}_{2}$ production of $L$. variegata decreased until a constant level was reached (Fig. 9). At 17:00 h the production increased to a new maximum, although the PFR of daylight decreased 


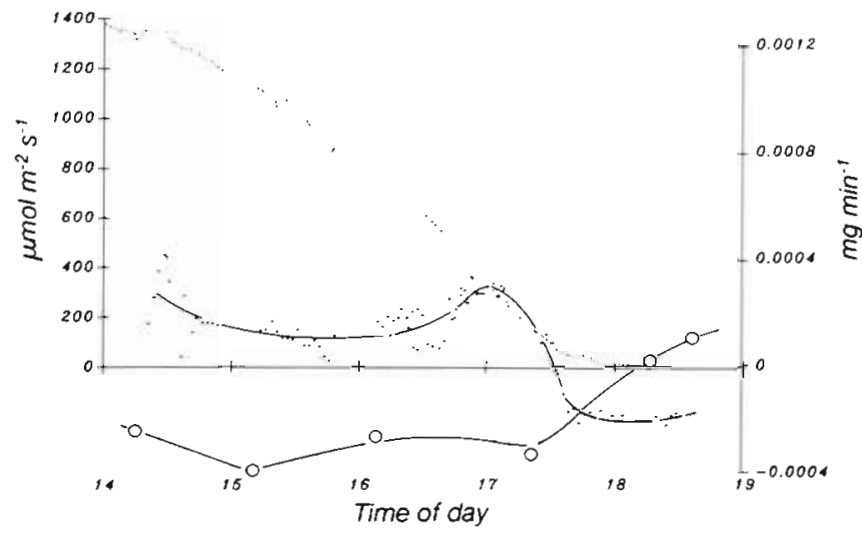

Fig. 9. Lobophora variegata. As in Fig. 7 with L. variegata disc as sample

continuously. Subsequently, $\mathrm{O}_{2}$ production decreased again corresponding to the decreasing PFR. Controlling the photosynthetic efficiency at $130 \mu \mathrm{mol} \mathrm{m} \mathrm{m}^{-2} \mathrm{~s}^{-1}$ red light, the production also decreased after the alga was inserted into the cuvette. A significant recovery, however, was measured only in the evening.

The brown alga Dictyota cervicornia grows in the sublittoral in Xiaodonghai Bay. Similar to Padina sp. and Sargassum glaucescens the lowest $F V / F m$ values were measured during low tide (14:50 h), and recovery occurred in the late afternoon (data not shown). In the $\mathrm{O}_{2}$ cuvette exposed at the water surface this alga was photodamaged, indicated by the change of the colour from yellow brown to green and by the loss of the photosynthetic activity. The increased UV-B radiation did not damage the alga because this spectral range was not transmitted by the glass window of the cuvette. However, when the incident PFR was prematurely reduced by $50 \%$ with the aid of a neutral glass density filter put on the glass window, photosynthesis continued to be active and a steady increase of the photosynthetic efficiency measured with red light was also observed.

The red alga Gracilaria tenuistipitata was cultivated in large pools in Haikou, where the level of water was almost constant during the day. We collected the algae about $30 \mathrm{~cm}$ below the water surface in turbid water where $54 \%$ of the full daylight was measured. In the morning the sky was grey. At about 10:30 h the cloudiness decreased and the sun came only temporarily through (Fig. 10). Due to the low PFR during the morning, $F v / F m$ did not significantly decrease before 11:15 h, indicating that photoinhibition occurred only after the PFR exceeded $500 \mu \mathrm{mol} \mathrm{m} \mathrm{m}^{-2} \mathrm{~s}^{-1}$. The $\mathrm{O}_{2}$ production curve during the morning (the top of the cuvette was about $30 \mathrm{~cm}$ below the water surface) resembles the PFR curve of daylight (Fig. 11). The photosynthetic activity does not show a constant max-

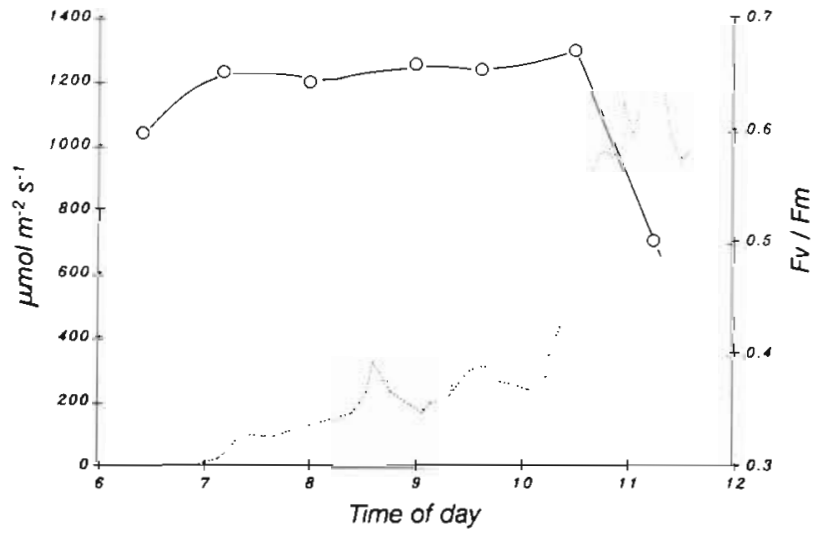

Fig. 10. Gracilaria tenuistipitata. As in Fig. 5, but with $G$. tenuistipitata from large pools in Haikou. Sky was cloudy in the morning. Cloudiness decreased at about 10:30 h, which also caused a decrease in the ratio of variable to maximum fluorescence

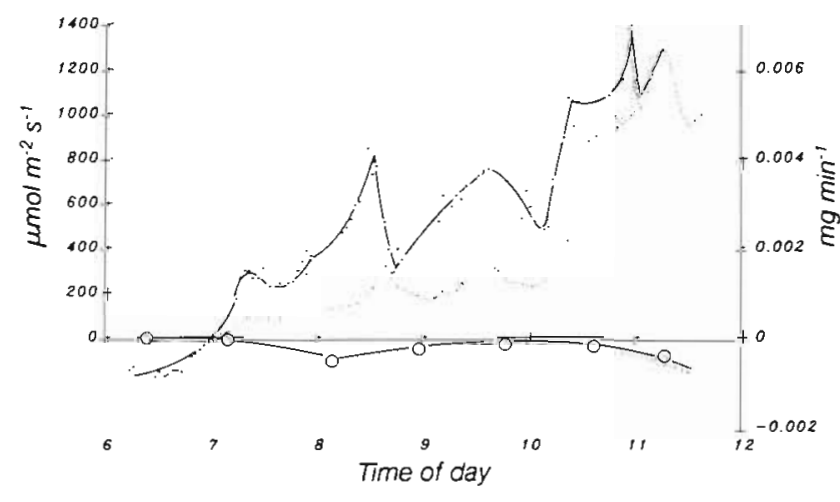

Fig. 11. Gracilaria tenuistipitata. As in Fig. 7 with G. tenuistipitata as sample. Cuvette was mounted under water in a large seawater pool in Haikou

imum level, because saturation of photosynthesis was not reached. The photosynthetic efficiency measured with red light shows no photoinhibition during the morning. At 11:15 h the value decreased slightly, indicating the beginning of a decrease in the photosynthetic efficiency. This result which differs from those of the fluorescence measurement may be due to the additional light attenuation by the cuvette or to the different algal sample or both.

In Xiaodonghai the seagrass Thalassia hemprichii was the only macrophyte growing in the lower intertidal zone in November 1990. We collected samples from plants, which were about $2 \mathrm{~cm}$ below the water surface at low tide. Until 14:00 h the sky was cloudy so that the PFR varied strongly (Fig.12). However, the lowest FV/Fm was found at low tide, i.e. not with the highest PFR in air, showing again the strong influence of both light reflection on the surface of water and the turbidity on the irradiance under water. Recovery com- 


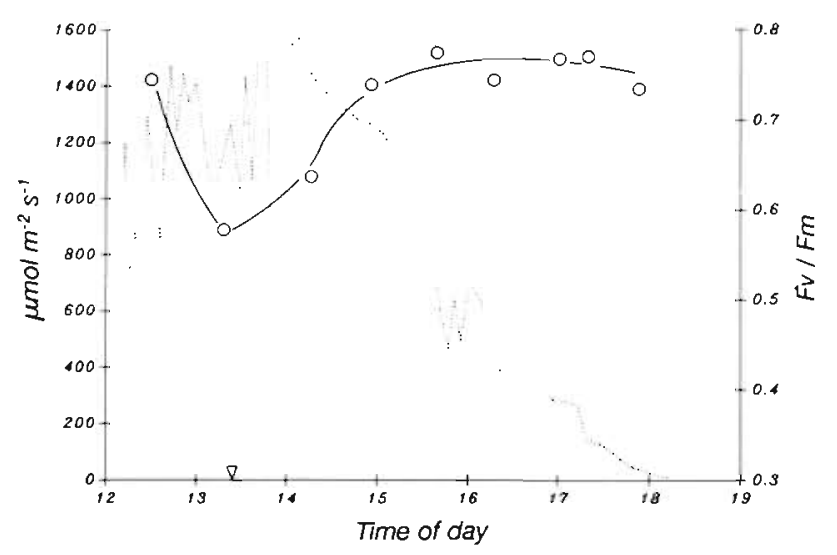

Fig. 12. Thalassia hemprichii. As in Fig. 5. This seagrass grows in the lower intertidal and upper subtidal zone in Xiaodonghai Bay

menced early in the afternoon, and full recovery was already reached at about 16:00 h. Simultaneous $\mathrm{O}_{2}$ measurements showed that the PFR during the afternoon was not high enough to saturate photosynthesis and no significant decrease of the photosynthetic efficiency measured with red light could be observed (data not shown). Apparently, T. hemprichii is able to cope with the light conditions in the lower intertidal zone. However, Fig. 13 shows that at very high PFR even

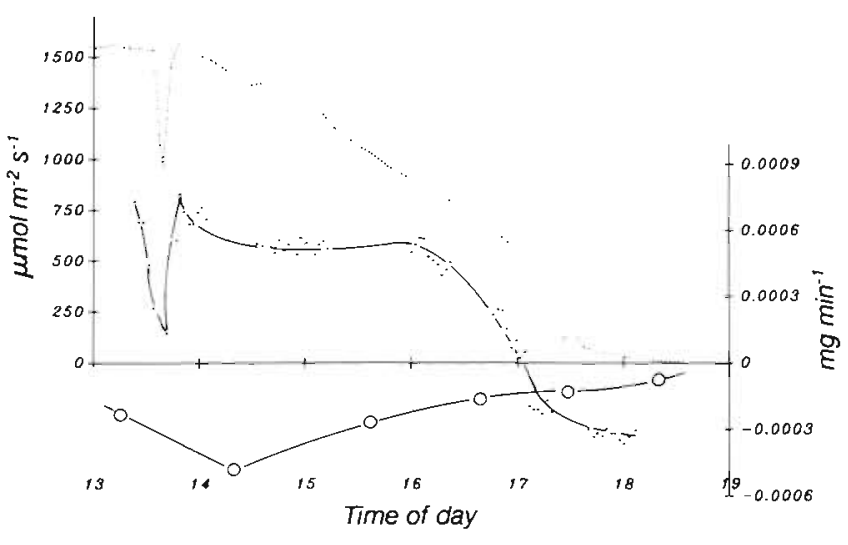

Fig. 13. Thalassia hemprichii. As in Fig. 7 with $T$ hemprichii disc as sample. Top of cuvette was placed above the surface of the seawater

$T$. hemprichii reduces its photosynthetic efficiency. Between 14:00 $\mathrm{h}$ and 16:00 h the saturation level of photosynthesis was reached, as $\mathrm{O}_{2}$ production remained constant although the PFR of daylight decreased continuously. At 14:15 h photoinhibition occurred. This may also be the reason why at 13:45 h the $\mathrm{O}_{2}$ production caused by daylight was higher than at $15: 00 \mathrm{~h}$, as a result of the reduction of the saturation level. The recovery of photosynthesis advanced from 15:40 $\mathrm{h}$ to the evening.

\section{DISCUSSION}

The photoinhibition in 4 brown algae, 1 red alga and 1 seagrass was investigated in the field. All of these organisms showed the same pattern of photoinhibition as we observed in different species in the cold temperate zone of Helgoland in the NE North Sea (Huppertz et al. 1990, author's unpubl. data). Photosynthetic activity depends on the actual photon fluence rate. A considerable degree of photoinhibition of photosynthesis was induced on sunny days, recovery commenced in the afternoon and full recovery was reached no later than the evening. A circadian periodicity of the activity or capacity was not observed. However, a dependence of photoinhibition of photosynthesis on the tides is evident (Figs. 4, $5 \& 12$ ). This was due to the high turbidity of the seawater, which was caused by both dynamite fishing by Chinese fishermen and a high number of typhoons causing a strong surf. The latter was not normal for this season. In addition, the motion of the water surface which changes the reflection of light also has an influence on the PFR under water. In the particular case of sunrays impinging at an acute angle on the water surface, as in autumn at Hainandao, the reflection of light at the water surface decreases the PFR under water considerably. Therefore, on many days the PFR under water was very low, and the algae did not show photoinhibition.

In Ulva rotundata it appears that photosynthetic capacity and, hence, efficiency is suppressed when high temperature and PFR act together (W. J. Henley et al. unpubl.). At Xiaodonghai a near-surface water temperature of about $29^{\circ} \mathrm{C}$ was measured at midday and about $26^{\circ} \mathrm{C}$ at $18: 00 \mathrm{~h}$. This shows that greater changes of the water temperature, which may be even less in the sublittoral, did not occur during the course of the day. Therefore, a significant influence of the change in the water temperature can be excluded. Data are unfortunately not sufficient to justify an influence of the short dusk period and the high temperature on the kinetics of photoinhibition and recovery of photosynthesis.

Different sensitivities of species to high PFRs at comparable conditions were observed. Dictyota cervicornia was already damaged by the higher PFR at the water surface. In $\mathrm{O}_{2}$ experiments Padina sp. showed no clear results, a significant increase of the photosynthetic efficiency during the late afternoon or in the evening and, hence, a recovery was not observed (data not shown). Short exposure to the higher PFRs at the water surface caused a strong decrease of $F v / F m$ (Fig. 3). In fluorescence measurements with sublittoral samples, however, the occurrence of photoinhibition and recovery during the course of a day was proved (Figs. 2 \& 4). Sargassum glaucescens (Fig. 6), Lobophora variegata 
(Fig. 8) and especially Thalassia hemprichii (Fig. 12) grew in the lower intertidal and upper subtidal zone and, hence, could cope with the high PFR at the water surface. The 2 algae and especially the seagrass showed a fast recovery of photosynthesis in the afternoon, although the PFR was still relatively high. A photodamage indicated by a loss of the photosynthetic activity or by an only partial recovery did not occur (Figs. $9 \& 13$ ). This points to a relation between photoinhibition and recovery of photosynthesis and the algal zonation.

Acknowledgements. I am indebted to Dr Inka tom Dieck (Biologische Anstalt Helgoland) for helpful cooperation, Prof. Dr Xia Bangmei (IOAS, Qingdao) for determining the species, the colleagues of the Senckenberg Gesellschaft Frankfurt and of the Academia Sinica, Qingdao, for giving me the opportunity to join the expedition. I thank the Max Planck Gesellschaft for bearing the costs of the flights, the Academia Sinica for the care during the expedition and the Deutsche Forschungsgemeinschaft for financial support. I also thank Prof. Dr W. Nultsch for critical reading of the manuscript.

\section{LITERATURE CITED}

Aro, E. M. Tyystjärvi, E., Nurmi, A. (1990). Temperaturedependent changes in Photosystem II heterogeneity of attached leaves under high light. Physiol. Plant. 79: 585-592

Demmig-Adams, B., Adams, W. W. III, Winter, K., Meyer, A., Schreiber, U., Pereira, J. S., Krüger, A., Czygan, F.-C., Lange, O. L. (1989). Photochemical efficiency of photosystem II, photon yield of $\mathrm{O}_{2}$ evolution, photosynthetic capacity, and carotenoid composition during the midday depression of net $\mathrm{CO}_{2}$ uptake in Arbutus unedo growing in Portugal. Planta 177: 377-387

Gao, K. (1990). Diurnal photosynthetic performance of Sargassum horneri. Jap. J. Phycol. 38: 163-165

Gong, H., Nilsen, S. (1989). Effect of temperature on photo-

This article was submitted to the editor inhibition of photosynthesis, recovery and turnover of the $32 \mathrm{kD}$ chloroplast protein in Lemna gibba. J. Plant Physiol. 135: 9-14

Greer, D. H., Berry, J. A., Björkman, O. (1986). Photoinhibition of photosynthesis in intact bean leaves: role of light and temperature, and requirement for chloroplast-protein synthesis during recovery. Planta 168: 253-260

Hanelt, D., Nultsch, W. (1990). Daily changes of the phaeoplast arrangement in the brown alga Dictyota dichotoma as studied in field experiments. Mar. Ecol. Prog. Ser. 61: $273-279$

Huppertz, K., Hanelt, D., Nultsch, W. (1990). Photoinhibition of photosynthesis in the marine brown alga Fucus serratus as studied in field experiments. Mar. Ecol. Prog. Ser. 66: $175-182$

Krause, G. H., Weis, E. (1991). Chlorophyll fluorescence and photosynthesis: the basics. Ann. Rev. Plant Physiol. Plant Mol. Biol. 42: 313-349

Nultsch, W., Pfau, J., Materna-Weide, M. (1987). Fluence and wavelength dependence of photoinhibition in the brown alga Dictyota dichotoma. Mar. Ecol. Prog. Ser. 41: 93-97

Nultsch, W., Pfau, J., Huppertz, K. (1990). Photoinhibition of photosynthetic oxygen production and its recovery in the subtidal red alga Polyneura hilliae. Bot. Acta 103: 62-67

Ögren, E. (1988). Photoinhibition of photosynthesis in willow leaves under field conditions. Planta 175: 229-236

Preez, D. R. du, Campell, E. E., Bate, G. C. (1990). Photoinhibition of photosynthesis in the surf diatom, Anaulus australis Drebes et Schulz. Bot. Marina 33: 539-543

Ramus, J., Rosenberg, G. (1980). Diurnal photosynthetic performance of seaweeds measured under natural conditions. Mar. Biol. 56: 21-28

Ramus, J. (1981). The capture and transduction of light energy. In Lobban, C. S., Wynne, M. J. (eds.) The biology of seaweeds. Blackwell Scientific Publications, Oxford, p. $458-493$

Richter, M., Rühle, W., Wild, A. (1990). Studies on the mechanism of photosystem II photoinhibition I. A two-step degradation of D1-protein. Photosynth. Res. 24: 229-235

Schreiber, U., Schliwa, U., Bilger, W. (1986). Continuous recording of photochemical and non-photochemical chlorophyll fluorescence quenching with a new type of modulation fluorometer. Photosynth. Res. 10: 51-62

Manuscript first received: November 19, 1991

Revised version accepted: March 3, 1992 